\title{
EFEITO DO TAMANHO DA SEMENTE, SUBSTRATO EAMBIENTE NA PRODUÇÃO DE MUDAS DE Copernicia Hospita MARTIUS ${ }^{1}$
}

\author{
Effect of seed size, substrate, and environment on the production of \\ Copernicia hospita Martius seedlings
}

\author{
Alexandre Bosco de Oliveira² ${ }^{2}$, Sebastião Medeiros Filho ${ }^{3}$,Antônio Marcos Esmeraldo Bezerra ${ }^{4}$
}

\begin{abstract}
RESUMO
A carnaúba hospedeira faz parte de um grupo de plantas da família Arecaceae, de relevante importância social e econômica para as regiões tropicais. Neste trabalho, objetivou-se determinar a influência do tamanho da semente, tipo de substrato e do ambiente na produção de mudas de carnaúba hospedeira (Copernicia hospita Martius). As sementes de diferentes tamanhos (pequena, média, grande e mistura) foram semeadas em substratos constituídos de areia vermelha + bagana de carnaúba + húmus (2,5:2,5:1 em volume) e solo + arisco + composto orgânico Polefértil ${ }^{\otimes}$ (2:2:1 em volume) e cultivadas em ambientes distintos (pleno sol e casa de vegetação). As variáveis analisadas foram: comprimento do limbo foliar principal, área foliar, diâmetro do coleto, comprimento da maior raiz e massa da matéria seca da parte aérea e radicular. O tamanho da semente exerceu efeito significativo sobre todas as variáveis. O substrato influenciou, significativamente, o comprimento do limbo e da maior raiz e área foliar. Quanto ao ambiente, as únicas variáveis não afetadas por esse fator foram as produções de matéria seca, tanto da parte aérea como radicular. Para a produção de mudas de $C$. hospita recomenda-se a utilização de sementes grandes, semeadas no substrato constituído de areia vermelha + bagana de carnaúba + húmus, em cultivo a pleno sol.
\end{abstract}

Termos para indexação: Carnaúba hospedeira, biometria da semente, meio de cultivo, sombreamento.

\section{ABSTRACT}

The 'Hostess' Carnauba belongs to a group of plants from the Arecaceae family, which is of relevant social and economic importance for tropical areas in Brazil. The objective of this research was to study the effect of the size of the seed, substrate, and environment on the production of seedlings of 'Hostess' Carnauba (Copernicia hospita Martius). Seeds of different sizes (small, medium, large, and a mixture of different sizes) were planted in different substrates composed of red sand + carnauba straw + humus $\left(2,5: 2,5: 1\right.$ in volume) and soil + dark sand + organic compost Polefértil ${ }^{\circledR}(2: 2: 1$ in volume), and cultivated in different environments (outdoors and indoors). The analyzed variables were: leaf length , leaf area, stem diameter, length of the longest root, and dry matter of the above and below ground parts. The size of the seed greatly affected all of the studied variables. Substrate type significantly affected leaf length, length of the longest root, and leaf area. The only variables not affected by the environment were of the dry matter from above and below ground parts. Thus, the results suggest that large seeds should be recommended for the production of $C$. hospita seedlings, and should be planted in a subtract composed of red sand + carnauba straw + humus for unshaded outdoor cultivation.

Index terms: Hostess Carnauba, seed biometry, culture medium, shade.

(Recebido em 28 de abril de 2008 e aprovado em 12 de dezembro de 2008)

\section{INTRODUÇÃO}

A família Palmae ou Arecaceae compreende um grupo de plantas de relevante importância econômica e ornamental, muito utilizadas em regiões tropicais, produzindo cocos, tâmaras, palmito, açúcar, sagu, óleo, cera, fibras e material para a construção de habitações rústicas, como folhas e estipe (LORENZI et al., 2004).

A Copernicia hospita Martius, conhecida popularmente como carnaúba hospedeira, é uma palmeira de tamanho médio, nativa das savanas e florestas secas de Cuba, podendo ser encontrada em montes e em inclinações. A parte específica do nome hospita, originado do latim, significa hospitalidade,em razão do fatode esta árvore ser um repouso hospitaleiro para uma larga variedade de pássaros (BROSCHAT \& MEEROW, 2000).

O êxito de um cultivo depende diretamente das potencialidades genéticas das sementes e da qualidade das mudas produzidas. Apesar disso, Santos et al. (2000) relatam que a obtenção de padrões de qualidade da muda

1Parte da Dissertação de mestrado do primeiro autor.

Eng. Agrônomo, M.Sc., Prof. Assistente I da Universidade Estadual do Piauí - Rua Almir Benvindo, s/n - Malvinas - 64.860-000 - Uruçuí, PI aleufc@gmail.com

${ }^{3} \mathrm{Eng}^{\circ}$. Agr ${ }^{\circ}$, Prof. Dr., Depto de Fitotecnia, CCA/UFC - Cx. P. 12.168 - 60356-001 - Fortaleza, CE - bolsista do CNPq - filho@ufc.br ${ }^{4} \mathrm{Eng}^{\circ}$. Agr ${ }^{\circ}$, Prof. Dr., Depto de Fitotecnia, CCA/UFC - Cx. P. 12.168, 60356-001 - Fortaleza, CE - esmeraldo@ufc.br 
e o aprimoramento das técnicas de viveiro não têm acompanhado a evolução conseguida em outras fases do plantio.

A influência do tamanho das sementes sobre a qualidade de mudas tem sido pesquisada com certa intensidade em várias espécies, porém é pouco frequente em espécies florestais (TORRES, 1994).

Quanto ao meio de cultivo, diversos materiais orgânicos e inorgânicos têm sido utilizados na formulação de substratos para a produção de mudas, havendo necessidade de se determinar os mais apropriados para cada espécie (LIMA et al., 2006; OLIVEIRA et al., 2008).

Conforme Oliveira et al. (2009), o ambiente de cultivo ou produção de mudas pode afetar positiva ou negativamente a qualidade das plantas. Fonseca et al. (2002) salientam que o sombreamento proporcionado pelo emprego de casas de vegetação pode ser utilizado para auxiliar no controle excessivo de temperatura. Porém, de acordo com Sentelhas \& Santos (1995), nem todas as alterações são benéficas.

O experimento foi conduzido com o objetivo de avaliar o efeito do tamanho da semente, do substrato e do ambiente na produção de mudas de C. hospita.

\section{MATERIAL E MÉTODOS}

A pesquisa foi desenvolvida em casa de vegetação pertencente ao Laboratório de Análises de Sementes e no Setor de Horticultura do Departamento de Fitotecnia da UFC, no Campus do Pici em FortalezaCE. As sementes foram extraídas de frutos de C. hospita colhidos em janeiro de 2007, no estádio visual de maturidade, com coloração roxo brilhante (Lorenzi et al., 2004), provenientes de 15 plantas matrizes localizadas na Fazenda Raposo, em Maracanaú-CE, classificadas com base no diâmetro, em quatro tamanhos: pequena (7,7-8,95 mm), média (8,96-10,21 mm), grande $(10,22-11,48$ $\mathrm{mm})$ e mistura, constituída de sementes retiradas aleatoriamente do lote inicial. Em seguida, estas foram semeadas em sacos de polietileno de 40 x $40 \mathrm{~cm}$ com 20 sementes cada, representando a parcela, visto que a emergência das espécies pertencentes a família Arecaceae pode ser lenta e irregular (Ferreira \& Gentil, 2006; Oliveira et al., 2009). As plantas foram cultivadas em dois substratos distintos: substrato 1 - solo de aluvião + arisco + composto orgânico Polefértil ${ }^{\circledR}$ (2:2:1 em volume) e substrato 2 - areia vermelha + bagana de carnaúba + húmus de minhoca (2,5:2,5:1 em volume). Nas Tabelas $1 \mathrm{e}$ 2 apresentam-se, respectivamente, as análises físicoquímicas dos substratos mencionados.

As plantas foram cultivadas em ambiente de casa de vegetação e a pleno sol até o final do experimento, aos 60 dias, após a semeadura. A temperatura e a umidade relativa do ar nos dois ambientes foram medidas com o auxílio de um higro-termômetro HT-210 SAMMAR ${ }^{\circledR}$, cujos valores médios obtidos no decorrer do ensaio são apresentados na Figura 1.

Aos 60 dias após a semeadura, foram coletadas as 12 plântulas mais uniformes de cada parcela e analisadas as variáveis: comprimento do limbo principal (CL), área foliar (AF), diâmetro do coleto (DC), comprimento da maior raiz (CR) e massa da matéria seca da parte aérea (MSPA) e das raízes (MSR).

Tabela 1 - Características físico-químicas do substrato 1 utilizado para a emergência e desenvolvimento de plântulas de Copernicia hospita. Fortaleza-CE, 2007.

\begin{tabular}{|c|c|c|c|c|c|c|c|c|c|c|c|}
\hline \multicolumn{5}{|c|}{ Composição Granulométrica (g/kg) } & \multirow{2}{*}{\multicolumn{2}{|c|}{$\begin{array}{c}\text { Classificação } \\
\text { Textural }\end{array}$}} & \multirow{2}{*}{\multicolumn{2}{|c|}{$\begin{array}{c}\text { Grau de } \\
\text { Floculação } \\
(\mathrm{g} / 100 \mathrm{~g})\end{array}$}} & \multicolumn{3}{|c|}{ Densidade $\left(\mathrm{g} / \mathrm{cm}^{3}\right)$} \\
\hline \multirow{2}{*}{$\begin{array}{c}\begin{array}{c}\text { Areia } \\
\text { Grossa }\end{array} \\
650\end{array}$} & \multirow{2}{*}{$\begin{array}{l}\text { Areia } \\
\text { Fina } \\
230\end{array}$} & \multirow{2}{*}{$\begin{array}{c}\text { Silte } \\
60 \\
\end{array}$} & \multirow{2}{*}{$\frac{\text { Argila }}{70}$} & \multirow{2}{*}{$\begin{array}{c}\begin{array}{c}\text { Argila } \\
\text { Natural }\end{array} \\
10\end{array}$} & & & & & \multirow{2}{*}{$\begin{array}{r}\text { Global } \\
1,56\end{array}$} & \multicolumn{2}{|r|}{ Partícula } \\
\hline & & & & & Areia $\mathrm{f}$ & nca & & & & & 2,61 \\
\hline \multicolumn{3}{|c|}{ Umidade $(\mathrm{g} / 100 \mathrm{~g})$} & \multirow{2}{*}{$\begin{array}{c}\text { pH } \\
\text { (água) }\end{array}$} & \multirow{2}{*}{$\begin{array}{c}\text { C.E } \\
(\mathrm{dS} / \mathrm{m})\end{array}$} & \multicolumn{7}{|c|}{ Complexo Sortivo $\left(\mathrm{cmol}_{\mathrm{c}} / \mathrm{kg}\right)$} \\
\hline $\begin{array}{c}0,033 \\
\mathrm{MPa}\end{array}$ & $\begin{array}{l}1,5 \\
\mathrm{MPa}\end{array}$ & $\begin{array}{c}\text { Água } \\
\text { útil }\end{array}$ & & & $\mathrm{Ca}^{2+}$ & $\mathrm{Mg}^{2+}$ & $\mathrm{Na}^{+}$ & $\mathrm{K}^{+}$ & $\mathrm{H}^{+}$ & $\mathrm{S}$ & $\mathrm{T}$ \\
\hline 3,93 & 3,41 & 0,52 & 6,5 & 2,99 & 3,50 & 1,90 & 0,52 & 1,79 & 2,81 & 7,7 & 10,5 \\
\hline \multirow{2}{*}{$\mathrm{V}(\%)$} & \multirow{2}{*}{$\begin{array}{l}\text { PST } \\
(\%)\end{array}$} & \multirow{2}{*}{$\begin{array}{c}\mathrm{C} \\
(\mathrm{g} / \mathrm{kg})\end{array}$} & \multirow{2}{*}{$\begin{array}{c}\mathrm{N} \\
(\mathrm{g} / \mathrm{kg})\end{array}$} & \multirow{2}{*}{$\mathrm{C} / \mathrm{N}$} & M.O & \multirow{2}{*}{\multicolumn{2}{|c|}{$\begin{array}{c}\text { P assimilável } \\
(\mathrm{mg} / \mathrm{kg})\end{array}$}} & \multicolumn{4}{|c|}{ Micronutrientes (ppm) } \\
\hline & & & & & $(\mathrm{g} / \mathrm{kg})$ & & & $\mathrm{Fe}$ & $\mathrm{Cu}$ & $\mathrm{Zn}$ & $\mathrm{Mn}$ \\
\hline 73 & 5 & 6,96 & 0,71 & 10 & 12,00 & & & 42,5 & 0,8 & 5,9 & 12,4 \\
\hline
\end{tabular}

(pH) potencial hidrogeniônico, (C.E) condutividade elétrica, (S) soma de bases, (T) capacidade de troca de cátions total a $\mathrm{pH} 7,0$, (V) saturação por bases, (PST) percentagem de sódio trocável, (M.O) matéria orgânica. 
Tabela 2 - Características físico-químicas do substrato 2 utilizado para a emergência e desenvolvimento de plântulas de Copernicia hospita. Fortaleza-CE, 2007.

\begin{tabular}{|c|c|c|c|c|c|c|c|c|c|c|c|}
\hline \multicolumn{5}{|c|}{ Composição Granulométrica (g/kg) } & \multirow{2}{*}{\multicolumn{2}{|c|}{$\begin{array}{l}\text { Classificação } \\
\text { Textural }\end{array}$}} & \multirow{2}{*}{\multicolumn{2}{|c|}{$\begin{array}{l}\text { Grau de Floculação } \\
(\mathrm{g} / 100 \mathrm{~g})\end{array}$}} & \multicolumn{3}{|c|}{ Densidade $\left(\mathrm{g} / \mathrm{cm}^{3}\right)$} \\
\hline \multirow{2}{*}{$\begin{array}{c}\text { Areia } \\
\text { Grossa }\end{array}$} & \multirow{2}{*}{$\begin{array}{c}\text { Areia } \\
\text { Fina } \\
260 \\
\end{array}$} & \multirow{2}{*}{$\begin{array}{c}\text { Silte } \\
100\end{array}$} & \multirow{2}{*}{$\begin{array}{c}\text { Argila } \\
60\end{array}$} & \multirow{2}{*}{$\begin{array}{c}\text { Argila } \\
\text { Natural }\end{array}$} & & & & & \multirow{2}{*}{$\begin{array}{c}\text { Global } \\
1,30\end{array}$} & \multicolumn{2}{|c|}{ Partícula } \\
\hline & & & & & Areia $\mathrm{f}$ & nca & & & & & 2,45 \\
\hline \multicolumn{3}{|c|}{ Umidade $(\mathrm{g} / 100 \mathrm{~g})$} & \multirow{2}{*}{$\begin{array}{c}\mathrm{pH} \\
\text { (água) }\end{array}$} & \multirow{2}{*}{$\begin{array}{l}\text { C.E } \\
(\mathrm{dS} / \mathrm{m})\end{array}$} & \multicolumn{7}{|c|}{ Complexo Sortivo $\left(\mathrm{cmol}_{\mathrm{c}} / \mathrm{kg}\right)$} \\
\hline $\begin{array}{l}0,033 \\
\mathrm{MPa}\end{array}$ & $\begin{array}{c}1,5 \\
\mathrm{MPa} \\
\end{array}$ & $\begin{array}{c}\text { Água } \\
\text { útil }\end{array}$ & & & $\mathrm{Ca}^{2+}$ & $\mathrm{Mg}^{2+}$ & $\mathrm{Na}^{+}$ & $\mathrm{K}^{+}$ & $\mathrm{H}^{+}$ & $\mathrm{S}$ & $\mathrm{T}$ \\
\hline 11,27 & 11,13 & 0,15 & 6,7 & 7,53 & 8,50 & 4,00 & 1,46 & 4,99 & 2,81 & 18,9 & 21,8 \\
\hline \multirow[t]{2}{*}{$\mathrm{V}(\%)$} & \multirow{2}{*}{$\begin{array}{l}\text { PST } \\
(\%)\end{array}$} & \multirow{2}{*}{$\begin{array}{c}\mathrm{C} \\
(\mathrm{g} / \mathrm{kg})\end{array}$} & \multirow{2}{*}{$\begin{array}{c}\mathrm{N} \\
(\mathrm{g} / \mathrm{kg})\end{array}$} & \multirow{2}{*}{$\mathrm{C} / \mathrm{N}$} & M.O & \multirow{2}{*}{\multicolumn{2}{|c|}{$\begin{array}{c}\text { P assimilável } \\
(\mathrm{mg} / \mathrm{kg})\end{array}$}} & \multicolumn{4}{|c|}{ Micronutrientes (ppm) } \\
\hline & & & & & $(\mathrm{g} / \mathrm{kg})$ & & & $\mathrm{Fe}$ & $\mathrm{Cu}$ & $\mathrm{Zn}$ & $\mathrm{Mn}$ \\
\hline 87 & 7 & 25,8 & 1,30 & 10 & 44,48 & & 59 & 42,46 & 0,80 & 5,85 & 12,37 \\
\hline
\end{tabular}

(pH) potencial hidrogeniônico, (C.E) condutividade elétrica, (S) soma de bases, (T) capacidade de troca de cátions total a pH 7,0, (V) saturação por bases, (PST) percentagem de sódio trocável, (M.O) matéria orgânica.
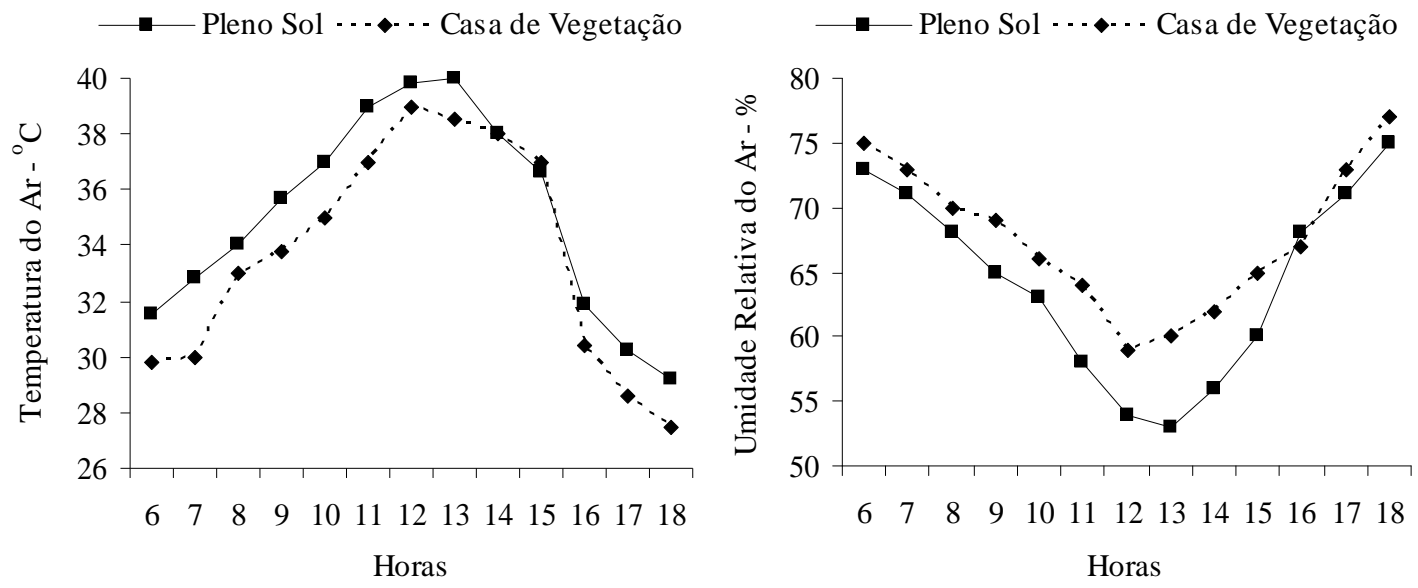

Figura 1 - Valores médios de temperatura e umidade relativa do ar ao longo do dia, nos ambientes de cultivo de Copernicia hospita. Fortaleza-CE, 2007.

A área foliar, em $\mathrm{cm}^{2}$, foi obtida com o medidor de área LI-3100 (Area Meter, Li-Cor., Inc, Lincoln, Nebraska, USA). Com o auxílio de uma régua graduada em centímetros, determinou-se o comprimento da maior raiz e o comprimento do limbo, que foi considerado como sendo a dimensão entre a superfície do solo e o ápice do limbo foliar. Obtevese o diâmetro do coleto, a 1,0 cm de altura em relação ao solo, usando um paquímetro digital, em milímetro, com precisão de duas casas decimais.

A massa da matéria seca da parte aérea (MSPA) e das raízes (MSR) das plântulas foi determinada após a secagem do material em estufa com circulação de ar forçado, a $80^{\circ} \mathrm{C}$ por 72 horas. As plântulas foram pesadas em uma balança de precisão de quatro casas decimais, sendo obtido o peso total da parcela, o qual foi dividido pelo número de plântulas, resultando na massa da matéria seca por plântula.

Adotou-se o delineamento experimental inteiramente casualizado (DIC) com quatro repetições de 20 sementes, em esquema fatorial $4 \times 2 \times 2$, totalizando 16 tratamentos, nos quais foram combinados quatro tamanhos de sementes (pequena, média, grande e mistura); dois substratos [areia vermelha + bagana de carnaúba + húmus de minhoca (2,5:2,5:1 em volume) e solo + arisco + composto orgânico Polefértil ${ }^{\circledR}$ (2:2:1 em volume)] e dois ambientes (pleno sol e casa de vegetação). A comparação das médias 
foi realizada por intermédio do teste de Tukey, a $5 \%$ de probabilidade (Banzatto \& Kronka, 2006).

\section{RESULTADOS E DISCUSSÃO}

O tamanho da semente exerceu efeito significativo sobre todas as variáveis (Tabela 3). Contudo, o substrato só influenciou significativamente o comprimento do limbo e da maior raiz e área foliar. Quanto ao ambiente, as únicas variáveis não afetadas por este fator foram as produções de matéria seca, tanto da parte aérea como radicular. Houve interação entre tamanho de semente e substrato, bem como ambiente e substrato para o diâmetro do coleto e a massa de matéria seca da parte aérea, respectivamente. A interação entre os três fatores foi significativa para a área foliar e o diâmetro do coleto.

A semente de tamanho grande, o substrato 1 e a casa de vegetação foram as condições que mais benefíciaram o desenvolvimento dàs folhias de $C$. hospita, representado, tanto pela variável comprimento do limbo, quanto pela área foliar (Tabela 4).

O tamanho da semente pode estar relacionado com a quantidade de reservas, sendo que em sementes maiores ocorre a síntese rápida de compostos secundários importantes para a germinação, maior produção de tecido fotossintético requerido no crescimento das plântulas e maior capacidade de sobrevivência em condições desfavoráveis (Surles et al., 1993; Ferreira \& Torres, 2000).

O menor desempenho das mudas cultivadas no substrato 2 pode estar relacionado com a grande quantidade de sais presente neste meio de cultivo, cuja condutividade elétrica do extrato de saturação (CE) esteve em torno de 7,53 dS.m ${ }^{-1}$ (Tabela 2).

Kämpf \& Fermino (2000) recomendam que os teores de sais no meio de cultivo devem ser mantidos em níveis aceitáveis, em torno de 1,0 dS.m ${ }^{-1}$, ou seja, valores bem inferiores aos obtidos no substrato 2. Desse modo, o mesmo pode ser considerado salino, pois de acordo com a classificação do "U.S. Salinity Laboratory" solos salinos são os que possuem $\mathrm{pH}$ inferior a 8,5, CE superior a $4 \mathrm{dS} . \mathrm{m}^{-1} \mathrm{e}$ percentagem de sódio trocável (PST) inferior a 15\% (DAKER, 1988). Fernandes et al. (2003), trabalhando com pupunheira (Bactris gasipaes H.B.K.), observaram reduções na área foliar bastante expressivas, cujos valores variaram de 63 a $89 \%$ em função dos níveis de salinidade. $\mathrm{O}$ efeito mais comum da salinidade é sobre o crescimento,em razão da redução da área foliar que afeta a assimilação de carbono pela planta, que, por sua vez, conduz a uma menor taxa fotossintética (Munns, 2002).

$\mathrm{O}$ ambiente de casa de vegetação proporcionou valores médios de comprimento do limbo e área foliar superiores ao cultivo em pleno sol (Tabela 4). Esses resultados foram obtidos, provavelmente, em virtude do ambiente sombreado de casa de vegetação proporcionar melhores condições para o desenvolvimento da parte aérea da planta, por meio da diminuição da luminosidade e temperatura, ao mesmo tempo em que proporcionou o aumento da umidade relativa do ar (Figura 1), resultando em menores taxas de transpiração foliar. Para Sentelhas \& Santos (1995) o emprego de casas de vegetação provoca

Tabela 3 - Resumo da análise de variância do comprimento do limbo principal (CL), área foliar (AF), diâmetro do coleto (DC), comprimento da maior raiz (CR) e massa da matéria seca da parte aérea (MSPA) e das raízes (MSR) de plântulas de Copernicia hospita oriundas de quatro tamanhos de sementes e cultivadas em dois tipos de substratos e duas condições ambientais. Fortaleza-CE, 2007.

\begin{tabular}{lccccccc}
\hline \multirow{2}{*}{ Fontes de variação } & \multirow{2}{*}{ GL } & \multicolumn{7}{c}{ Quadrados médios } \\
\cline { 3 - 8 } & & CL & AF & DC & CR & MSPA & MSR \\
\hline Tamanho semente (T) & 3 & $20,44^{* *}$ & $9,21^{* *}$ & $1,2525^{* *}$ & $83,41^{* *}$ & $0,0243^{* *}$ & $0,0033^{* *}$ \\
Substrato (S) & 1 & $7,16^{*}$ & $7,30^{*}$ & $0,0971^{\mathrm{ns}}$ & $93,10^{* *}$ & $0,0006^{\mathrm{ns}}$ & $0,0001^{\mathrm{ns}}$ \\
Ambiente (A) & 1 & $77,74^{* *}$ & $76,44^{* *}$ & $0,0001^{*}$ & $62,43^{* *}$ & $0,0007^{\mathrm{ns}}$ & $0,0002^{\mathrm{ns}}$ \\
(T) x (S) & 3 & $2,87^{\mathrm{ns}}$ & $0,91^{\mathrm{ns}}$ & $0,4825^{*}$ & $2,93^{\mathrm{ns}}$ & $0,0006^{\mathrm{ns}}$ & $0,00004^{\mathrm{ns}}$ \\
(T) x (A) & 3 & $3,68^{\mathrm{ns}}$ & $2,30^{\mathrm{ns}}$ & $0,1843^{\mathrm{ns}}$ & $3,68^{\mathrm{ns}}$ & $0,0003^{\mathrm{ns}}$ & $0,00001^{\mathrm{ns}}$ \\
(S) x (A) & 1 & $2,64^{\mathrm{ns}}$ & $6,19^{\mathrm{ns}}$ & $0,0024^{\mathrm{ns}}$ & $1,09^{\mathrm{ns}}$ & $0,0022^{*}$ & $0,00002^{\mathrm{ns}}$ \\
(T) x (S) x (A) & 3 & $2,77^{\mathrm{ns}}$ & $8,50^{* *}$ & $0,0055^{*}$ & $6,99^{\mathrm{ns}}$ & $0,0004^{\mathrm{ns}}$ & $0,00004^{\mathrm{ns}}$ \\
Resíduo & 48 & 1,48 & 1,78 & 0,17015 & 5,92 & 0,0004 & 0,00007 \\
\hline CV (\%) & & 5,83 & 22,43 & 10,33 & 13,38 & 12,12 & 15,11 \\
\hline
\end{tabular}

ns, *, ** não significativo, significativo a $5 \%$ e $1 \%$ de probabilidade pelo teste $\mathrm{F}$, respectivamente.

$\mathrm{CV}$ - coeficiente de variação 
alterações em diversos elementos meteorológicos, permitindo a produção de culturas em locais ou períodos cujas condições climáticas são hostis.

O diâmetro do coleto das mudas de C. hospita foi beneficiado com o uso de sementes grandes, as quais diferiram significativamente das demais classes de tamanho (Tabela 4). O maior diâmetro de coleto é uma característica desejável em mudas, porque garante maior sustentação (Farias et al., 1997; Tucci et al., 2007). Essa variável deve ser utilizada como o melhor dos indicadores de padrão de qualidade, pois com base nela, mudas delgadas, de grande altura, devem ser refugadas.

Os melhores resultados para o comprimento da maior raiz foram encontrados nos tratamentos com sementes das classes de tamanho grande e mistura, bem como, no cultivo com substrato 2 , em ambiente a pleno sol (Tabela 4). Leishman \& Westoby (1994) relataram que sementes de tamanho maior têm sido correlacionadas com maiores taxas de crescimento inicial de plântulas. Isso poderia aumentar a probabilidade de sucesso durante o estabelecimento das plântulas, uma vez que o rápido crescimento da parte aérea e raiz possibilitariam o aumento da taxa de fotossíntese pela folha, bem como, melhor aproveitamento das reservas nutricionais e hídricas do solo (Haig \& Westoby, 1991). As sementes maiores produzem plântulas mais vigorosas, provavelmente, porque possuem maior quantidade de material de reserva, maior nível de hormônios e maior embrião (Surles et al., 1993). Maior quantidade de reserva, por sua vez, aumenta a possibilidade de sucesso no estabelecimento da plântula, tendo em vista que possibilita a sua sobrevivência por um tempo maior em condições ambientais que ainda não permitem o aproveitamento das reservas nutricionais e hídricas do solo e a realização da fotossíntese (Haig \& Westoby, 1991).

O maior desenvolvimento das raízes das plantas cultivadas no substrato constituído de areia vermelha + bagana de carnaúba + húmus de minhoca pode estar relacionado com suas características físico-químicas (Tabela 2). Klepper (1990) concorda que a capacidade das raízes em explorar o solo depende das características físicas e químicas do solo, tais como o impedimento mecânico ao crescimento das raízes, umidade do solo, textura do solo e fertilidade. O suprimento de água e nutrientes, a temperatura, a resistência mecânica, a aeração do solo e as interações entre esses fatores influenciam o crescimento de raízes e suas funções (Freitas et al., 2005).

Tabela 4 - Comprimento do limbo principal (CL), área foliar (AF), diâmetro do coleto (DC), comprimento da maior raiz (CR) e massa da matéria seca da parte aérea (MSPA) e das raízes (MSR) de plantas de Copernicia hospita oriundas de quatro tamanhos de sementes e cultivadas em dois tipos de substratos e duas condições ambientais. Fortaleza-CE, 2007.

\begin{tabular}{|c|c|c|c|c|c|c|}
\hline Tratamentos & $\mathrm{CL}$ & $\mathrm{AF}$ & $\mathrm{DC}$ & $\mathrm{CR}$ & MSPA & MSR \\
\hline & $\ldots . . \mathrm{cm} \ldots . . .$. & $\ldots . . \mathrm{cm}^{2} \ldots .$. & ....mm.... & $\ldots . . \mathrm{cm} \ldots . .$. & \multicolumn{2}{|c|}{ 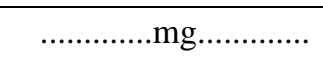 } \\
\hline & \multicolumn{6}{|c|}{ Tamanho da semente $\cdot$} \\
\hline Grande & $22,27 \mathrm{a}$ & $6,82 \mathrm{a}$ & 4,38 a & $20,75 \mathrm{a}$ & $209,05 \mathrm{a}$ & $72,11 \mathrm{a}$ \\
\hline Média & $20,50 \mathrm{bc}$ & $5,87 \mathrm{ab}$ & $3,89 \mathrm{~b}$ & $17,77 \mathrm{~b}$ & $144,88 \mathrm{~b}$ & $49,88 \mathrm{~b}$ \\
\hline Pequena & $19,57 \mathrm{c}$ & $4,98 \mathrm{~b}$ & $3,72 \mathrm{~b}$ & $15,29 \mathrm{c}$ & $115,94 \mathrm{c}$ & $37,50 \mathrm{c}$ \\
\hline Mistura & $21,08 \mathrm{~b}$ & $6,13 \mathrm{ab}$ & $3,99 \mathrm{~b}$ & $18,89 \mathrm{ab}$ & $161,51 \mathrm{~b}$ & $56,29 \mathrm{~b}$ \\
\hline \multirow[t]{2}{*}{ DMS } & 1,14 & 1,26 & 0,39 & 2,29 & 18,00 & 7,67 \\
\hline & \multicolumn{6}{|c|}{$\cdots$ Substrato } \\
\hline 1 & $21,19 \mathrm{a}$ & $6,29 \mathrm{a}$ & $4,03 \mathrm{a}$ & $16,97 \mathrm{~b}$ & $154,78 \mathrm{a}$ & $53,00 \mathrm{a}$ \\
\hline 2 & $20,52 \mathrm{~b}$ & $5,61 \mathrm{~b}$ & $3,96 \mathrm{a}$ & $19,38 \mathrm{a}$ & $160,90 \mathrm{a}$ & $54,88 \mathrm{a}$ \\
\hline \multirow[t]{2}{*}{ DMS } & 0,61 & 0,67 & 0,21 & 1,22 & 9,62 & 4,10 \\
\hline & \multicolumn{6}{|c|}{$\cdots$ Ambiente } \\
\hline Casa de vegetação & $21,95 \mathrm{a}$ & $7,04 \mathrm{a}$ & $3,99 \mathrm{a}$ & $17,19 \mathrm{~b}$ & $161,07 \mathrm{a}$ & $52,14 \mathrm{a}$ \\
\hline Pleno sol & $19,75 \mathrm{~b}$ & $4,86 \mathrm{~b}$ & $4,00 \mathrm{a}$ & $19,16 \mathrm{a}$ & $154,61 \mathrm{a}$ & $55,75 \mathrm{a}$ \\
\hline DMS & 0,61 & 0,67 & 0,21 & 1,22 & 9,62 & 4,10 \\
\hline
\end{tabular}

Médias seguidas pela mesma letra na coluna não diferem entre si pelo, pelo teste Tukey a 5\% de probabilidade. DMS - diferença mínima significativa 
As plântulas cultivadas a pleno sol apresentaram maior comprimento da raiz (CR) do que aquelas mantidas em casa de vegetação. $O$ aumento da radiação solar naquele ambiente pode ter aumentado a taxa de fotossíntese, proporcionando melhor desenvolvimento das raízes, por meio da relação fonte-dreno entre a parte aérea e a raiz. Em suma, esses resultados concordam com a explicação de Sentelhas \& Santos (1995), pois segundo esses autores, apesar do emprego de casas de vegetação provocar alterações em diversos elementos meteorológicos, tais como radiação solar, temperatura do ar, umidade relativa do ar, evapotranspiração e luminosidade, possibilitando o cultivo em regiões adversas, essas alterações nem sempre são benéficas para os vegetais.

As produções de matéria seca, tanto da parte aérea quanto da raiz, apresentaram comportamento semelhante, obtendo-se diferença significativa para a semente grande, na qual foram obtidos valores médios superiores aos demais tamanhos (Tabela 4). Nos tratamentos com diferentes substratos e ambientes não se observou diferença significativa pelo teste de Tukey $(\mathrm{P}=0,05)$, apesar de ter sido obtido efeito significativo para o fator ambiente, por meio do teste $\mathrm{F}(\mathrm{P}=0,05)$. Pimentel-Gomes (2000) explica que em alguns casos o F consegue detectar efeito significativo, mas não há distinção das médias pelo teste de Tukey devido a proximidade dos valores.

A redução da radiação solar provocada pela casa de vegetação pode ter causado estiolamento das mudas produzidas nesse ambiente (Fonseca et al., 2002), no qual foram obtidas mudas com maior comprimento do limbo e área foliar, em detrimento do diâmetro do coleto e massa de matéria seca da parte aérea, cujos valores não diferiram significativamente entre os ambientes distintos (Tabela 4). Nesse sentido, o vigor da muda deve estar associado a maior produção de biomassa, maior diâmetro do colo e menor altura. Esses dados revelam que as condições climáticas proporcionadas pelo ambiente de casa de vegetação podem provocar efeitos adversos no comportamento da espécie $C$. hospita. Possivelmente, mudas obtidas nessas condições e sem um bom trabalho de aclimatação, teriam o desenvolvimento comprometido no campo.

\section{CONCLUSÃO}

Para a produção de mudas de Copernicia hospita, recomenda-se a utilização de sementes grandes, semeadas em substrato constituído de areia vermelha + bagana de carnaúba + húmus (2,5:2,5:1 em volume), em cultivo a pleno sol.

\section{REFERÊNCIAS BIBLIOGRÁFICAS}

BANZATTO, D.A.; KRONKA, S.N. Experimentação agrícola. 4.ed. Jaboticabal: UNESP, 2006. 237 p.

BROSCHAT, T.K.; MEEROW, A.W. Ornamental palm horticulture. Gainesville: University of Florida, 2000. 255p.

DAKER, A. A água na agricultura. 7. ed. Rio de Janeiro: F.Bastos, 1988. v.3, 453p.

FARIAS, V.C.C.; COSTA, S.S.; BATALHA, L.F P. Análise de crescimento de mudas de cedrorana (Cedrelinga catenaeformis (Ducke) Ducke) cultivadas em condições de viveiro. Revista Brasileira de Sementes, Brasília, v.19, n.2, p.193-200, 1997.

FERNANDES, A.R.; CARVALHO, J.G.; CURI, N.; GUIMARÃES, P. de T.G.; PINTO, J.E.B.P. Crescimento de mudas de pupunheira (Bactris gasipaes H.B.K) sob diferentes níveis de salinidade. Revista Ciência e Agrotecnologia, Lavras, v.27, n.2, p.278-284, 2003.

FERREIRA, M.G.R.; TORRES, S.B. Influência do tamanho das sementes na germinação e no vigor de plântulas de Acacia Senegal (L.) Willd. Revista Brasileira de Sementes, Brasília, v.22, n.1, p.271-275, 2000.

FERREIRA, S.A. do N.; GENTIL, D.F. de O. Extração, embebição e germinação de sementes de tucumã (Astrocaryum aculeatum). Revista Acta Amazônica, Manaus, v.36, n.2, p.141-146, 2006.

FONSECA, E.P.; VALÉRI, S.V.; MIGLIORANZA, E.; FONSECA, N.A.N.; COUTO, L. Padrão de qualidade de mudas de Trema micrantha (L.) Blume, Produzidas sob diferentes períodos de sombreamento. Revista Árvore, Viçosa, v.26, n.4, p.515-523, 2002.

FREITAS, T.A.S.; BARROSO, D.G.; CARNEIRO, J.G.A.; PENCHEL, R.M.; LAMÔNICA, K.R.;

FERREIRA, D.A. Desempenho radicular de mudas de eucalipto produzidas em diferentes recipientes e substratos. Revista Árvore, Viçosa, v.29, n.6, p.853$861,2005$.

HAIG, D.; WESTOBY, M. Seed size, pollination casts and angiosperm success. Evolutionary Ecology, Tucson, v.5, n.2, p.231-247, 1991. 
KÄMPF, A.N.; FERMINO, M.H. Substratos para plantas: a base da produção vegetal em recipientes. In: ENCONTRO NACIONAL SOBRE SUBSTRATOS PARA PLANTAS, 2000, Porto Alegre. Anais... Porto Alegre: Gênesis, 2000. p.312.

KLEPPER, B. Root growth and water uptake. In: STEWART, D. R.; NIELSEN, D. R. (Eds.) Irrigation of agricultural crops. Madison: ASA/CSSA/SSSA, 1990. p. 282-322.

LEISHMAN, M.R.; WESTOBY, M. The role of large seed size in shaded conditions: experimental evidence.

Functional Ecology, London, v.8, n.2, p.205-214, 1994.

LIMA, R.L.S. SEVERINO, L.S.; SILVA, M.I.L.; VALE, L.S.; BELTRÃO, N.E.M. Volume de recipientes e composição de substratos para produção de mudas de mamoneira. Ciência e Agrotecnologia, Lavras, v.30, n.3, p.480-486, 2006.

LORENZI, H.; SOUZA, H.M. de; CERQUEIRA, L.S.C. de; COSTA, J.T. de M.; FERREIRA, E. Palmeiras brasileiras e exóticas cultivadas. Nova Odessa: Plantarum, 2004. 432 p.

MUNNS, R. Comparative physiology of salt and water stress. Plant, Cell and Environment, Oxford, v. 25, p. 239-250, 2002.

OLIVEIRA, A. B. de; HERNANDEZ, F.F.F.; ASSIS JUNIOR, R.N. de. Pó de coco verde, uma alternativa de substrato na produção de mudas de berinjela. Revista Ciência Agronômica, Fortaleza, v.39, n.1, p.39-44, 2008.
OLIVEIRA, A.B. de; MEDEIROS FILHO, S.; BEZERRA, A.M.E.; BRUNO, R. de L.A. Emergência de plântulas de Copernicia hospita Martius em função do tamanho da semente, do substrato e do ambiente. Revista Brasileira de Sementes, Brasília, v.31, n.1, p.281-287, 2009.

PIMENTEL-GOMES, F. Curso de estatística experimental. 14.ed. Piracicaba: ESALQ, 2000. 477p.

SANTOS, C.B.; LONGHI, S.J.; HOPPE, J.M.; MOSCOVICH, F.A. Efeito do volume de tubetes e tipos de substratos na qualidade de mudas de Cruptomeria japonica (L.F.) D. Don. Ciência Florestal, Santa Maria, v.10, n.2, p.1-15, 2000.

SENTELHAS, P.C.; SANTOS, A.O. Cultivo protegido: aspectos microclimáticos. Revista Brasileira de Horticultura Ornamental, Campinas, v.1, n.2, p.108-115, 1995.

SURLES, S.E.; WHITE, T.L.; HODGE, G.P. Relationships among seed weight components, seedling growth traits, and predicted field breeding values in slash pine. Canadian Journal Forest Research, Ottawa, v.23, n.8, p.1550-1556, 1993.

TORRES, S.B. Influência do tamanho das sementes de Acacia gomifera no desenvolvimento das mudas. Agropecuária Catarinense, Santa Catarina, v.7, n.2, p.5, 1994.

TUCCI, M.L.S.; BOVI, M.L.A.; MACHADO, E.C.; SPIERING, S.H. Seasonal growth variation of peach palms cultivated in containers under subtropical conditions. Scientia agrícola, Piracicaba, v.64, n.2, p.138-146, 2007. 